\title{
A study of clay tobacco pipes in Tunis. Were they traded to Gozo (Malta)?
}

\author{
By JOHN WOOD
}

\begin{abstract}
SUMMARY: A significant number of clay tobacco pipes in the style of the Ottoman 'chibouk' can be found in museums and private collections on the islands of Malta and Gozo. Indeed the smoking of these pipes remains a folk memory with the majority of senior citizens. It became obvious that very few of these artefacts were made locally and that the Maltese, being at the geographical centre of Mediterranean culture, might have received their imports from anywhere.

In 19th-century Tunisia (Malta's nearest North African neighbour) three-quarters of the European population were Maltese migrants. Therefore, this study set out to discover whether Tunisia was a source of supply.

In Tunis it became obvious that although clay tobacco pipes had turned up in local excavations, little attention had been paid to them and a fuller examination was welcomed. A by-product of this examination was to establish a locally made Tunis pipe, although little evidence was found for trade to Malta in that particular commodity.
\end{abstract}

I

\section{INTRODUCTION}

Qallaline potteries were in operation in Tunis from the late 16 th century until the 1920 s. The chibouk style tobacco pipe, called sebsi ( $\mathrm{pl}$. sbesi) in Tunisia, is a bowl usually made of clay with separate stem and mouthpiece which was in use throughout the Mediterranean, becoming increasingly more common from the 17 th to early 20 th centuries. It may be found in use even now in Morocco. ${ }^{1}$ Often a great deal of trouble was taken to decorate these bowls making them attractive items in their own right. They turn up frequently on land and underwater sites and have been the subject of study by various authors. In describing these artefacts I am following the terminology used by Rebecca Robinson. $^{2}$
II

GOZO

In 1992 this author published a description of some 22 clay tobacco pipes then in a reserve collection in Gozo's Museum of Archaeology. ${ }^{3}$ Of those pipes only two have known origins - and both of these are outside the islands, i.e., Bulgaria and France.

There seems to have been little tradition for making chibouk pipes in the Maltese Islands, although one resident of Rabat remembers an old man in the Bir Riebu area who was making clay pipe bowls in the mid 1930s. They were not sold as a business venture. The same woman says that North African nationals sold similar pipes: 'They were cream coloured with nice shapes, they were curved, they cost two pence halfpenny each. They used to sell sweet sedge root [cyperus esculentus] 
and pipes in a bag over their shoulder.' There is more information from an 80-year-old resident of Zejtun: 'There was a man who made pipes out of clay, he worked with his hands [no moulds]. Red ones used to be imported, the Turks [N. Africans] used to bring them, the cups were imported and then a thin reed inserted for smoking them.'

In the 19 th century there was considerable trade between the Maltese Islands and their nearest North African neighbour Tunisia. The Maltese at one time comprised over three-quarters of the European population in Tunis itself. The small Maltese trader found it easy to fill his speronara (sailing ship of 50-150 tons) with European textiles, metalware, gunpowder, tobacco and wine, and distribute these goods along the African coast in exchange for oil, dates, hides, cattle and cereals. As this trade grew steadily through the period there came into existence in these African ports an increasing number of openings for Maltese mercantile agents, hawkers, tobacconists, wine shop proprietors, boatmen, porters and carters.

Maltese hawkers, shopkeepers and masters of speronara controlled most of the coastal trade of Tunisia. Maltese boatmen and carriagemen also played an important part in the life of the city. With so much coastal trade in the hands of Maltese speronaras it appears that emigrants found it as cheap and simple to move about in these small vessels of their friends and relatives as to book passages in larger ships sailing direct. The skipper of a Maltese speronara might charge 2s. or so for the 200 mile crossing to Tunis. There were also migrants who became disillusioned for one reason or another and returned home. ${ }^{4}$

It is at least possible, given the thriving pottery industry in Tunisia and its proximity to Malta (Fig. 1), that pipes were imported into Malta by those traders. I therefore set out to make a direct

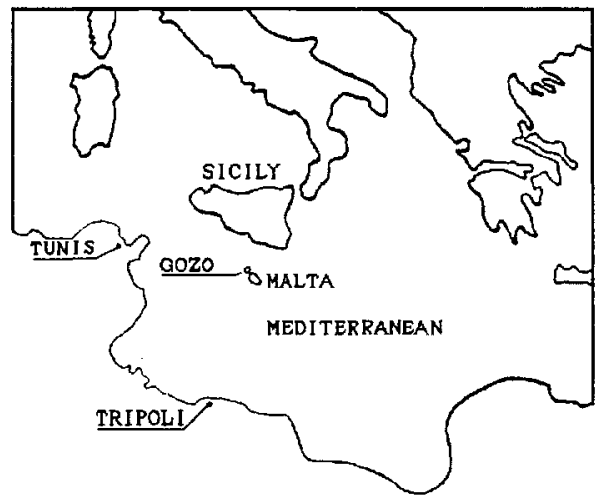

FIG. 1

The Maltese Islands
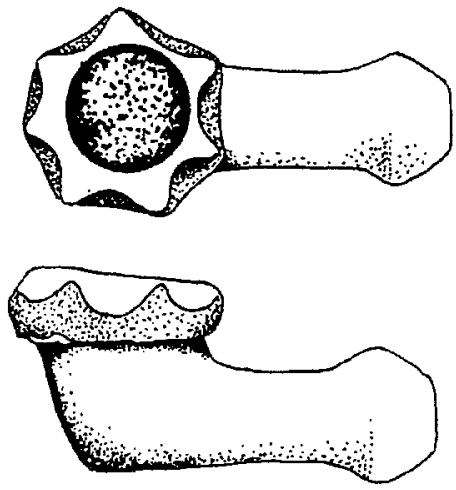

FIG. 2

T9a
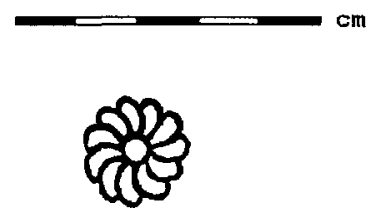

FIG. 3

Maker's mark? Not to scale

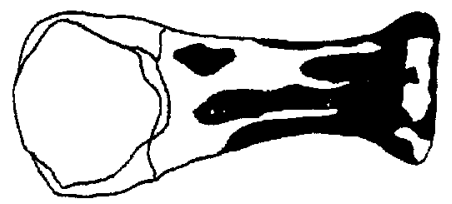

FIG. 4

T9c

comparison between the Gozitan and the Tunis collections.

III

\section{TUNIS}

With the kind permission of Dr Daoulatli, Director of the Institute National du Patrimoine in Tunis, I was able to inspect their reserve collection kept in the 16th-century palace Dar Othman (conservator M. Ben Mami). This palace has recently been restored and today houses the offices of the National Heritage Institute's Medina Department.

There are several hundred complete or fragmentary pipes in the Dar Othman collection which, being restricted in time, I decided to analyse superficially in terms of type, decoration, clay, origin and familiarity or oddity of design. The ' $\mathrm{T}$ ' numbering sequence is mine, catalogue numbers are the 'excavators'. Of the Tunis collection, in 
approximate terms, two-thirds of the 700 or so pieces are similar in design. T9a (Fig. 2) is the typical example, the body varies in colour between off-white and pinkish. Many have seven thumbsize indentations on the rim of the bowl, which is rarely square with the shank. A pipe of comparable style was also found in Borj El Kebir, Djerba, and the Musee-Kasbah, Sfax. A maker's mark (Fig. 3) occurs under a very similar bowl to T9a. They were possibly made at the Qallaline potteries close to Bab Souika on the east side of the Medina. The fact that similar glazes and oxides were used on T9b (not illustrated) and T9c (Fig. 4) which has a white tin glaze with haphazard cobalt blue decoration, lends weight to this idea (see Appendix).

Most of these pipes came from within the Kasbah during excavations directed by Abdclaziz Daoulatli, although a few were found in the fortress on Chekli Island on the north side of Lac de Tunis.

\section{IV}

\section{THE DAR OTHMAN COLLECTION}

From 1574 until the French protectorate in 1883 Tunisia was part of the Ottoman Empire, although, during the Husaynid period from 1705 onwards, Turkish authority was nominal. Even so many Turkish soldiers were garrisoned in the capital and surrounding areas such as Beja and El Kef. The Turks appear to have imported some aspects of their culture and their influence is noticeable in parts of this collection.

T5 (Fig. 5) and its twin, made from a finebodied cream colour clay, are unusual in that they have a ventral loop moulded centrally on the shank. A similar device occurs on an African pipe of typical 17th-century form from the wrecked Portuguese ship Santo Antonio de Tanna at Mombasa 1697. The hole was used 'For securing a removable stem to the bowl'. ${ }^{5}$ In south-east Asia there are pipes where the loop forms a bridge from bowl to stem on the dorsal ridge. It was suggested that this was a means of suspending the pipe when not in use. ${ }^{6} \mathrm{~T} 7$ cat. no. TL4, in pale terracotta (Fig. 6), is approximately two-thirds the size of most other pipes. This might suggest it is an early example dating from the time when tobacco was relatively expensive, although stylistically (with the keel) it should be late 17 th century or after. ${ }^{7} \mathrm{~T} 8$ cat. no. BL 27, the lily-shaped bowl, is of terracotta (Fig. 7) and was widespread after $1850 .^{8} \mathrm{~T} 11$ (Fig. 8) a common shape from the early 18 th century and later has a dark cream body with orange slip. T19, a disc-based shape (Fig. 9), in coffee brown

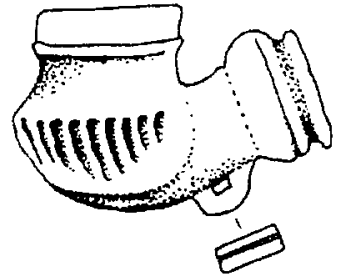

FIG. 5

T5

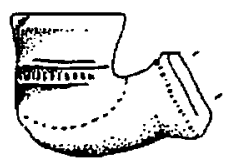

FIG. 6

T7 Cat. no. TL4
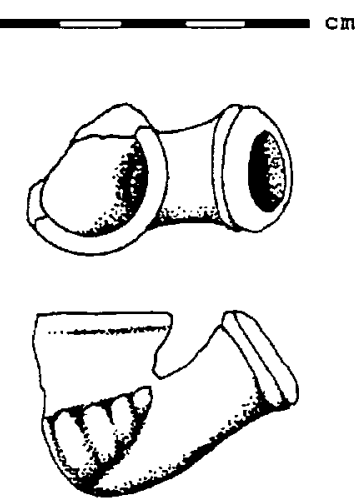

FIG. 7

T8 Cat. no. BL 27
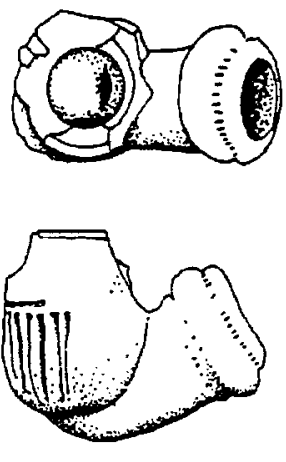

FIG. 8

T11

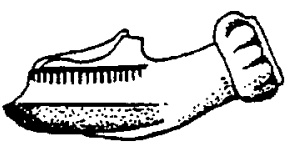

FIG. 9

T19 


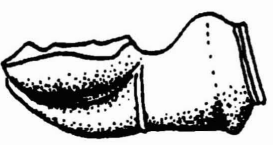

FIG. 10

T20 Cat. no. KN 12

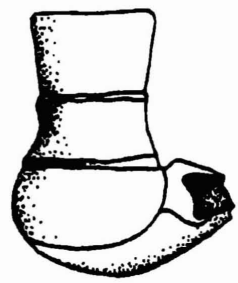

FIG. 11

T22

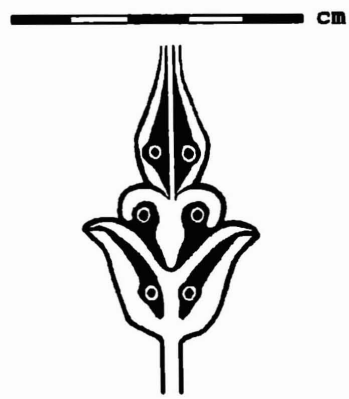

FIG. 12

Decoration on T24 Cat. no. B2 11. Not to scale

clay, which has not been found in Gozo, is known through many illustrations as being common throughout the Ottoman sphere, one good example is 'Lighting the Pipe', painted by Savvidis in 1899.' It is thought to be mid 19th century in style. The fine earthenware body, similar to pipeclay, T20 cat. no. KN12 (Fig. 10) is unique in this particular collection.

T22 in orange clay has an 18th- to early 19thcentury form common to both collections (Fig. 11). T24 cat. no. B2 11; the decorative element on this pipe is practically identical to the 'squidlike volutes' (Fig. 12) found on meerschaums at Corinth. ${ }^{10}$ T50 (Fig. 13) cat. no. B2 22 has a buff body, long faceted stem with incised decoration and a sacklike bowl. This pipe has a typical 'local' feel to Tunis.

\section{V}

The following features were found to be common in both collections.

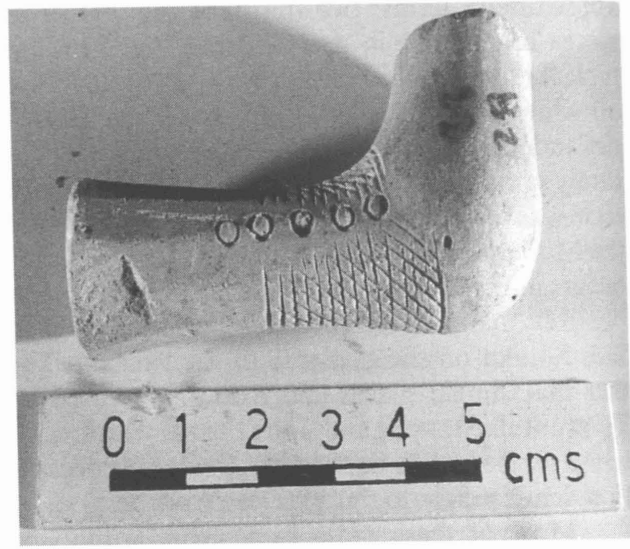

FIG. 13

T50 Cat. no. B2 22
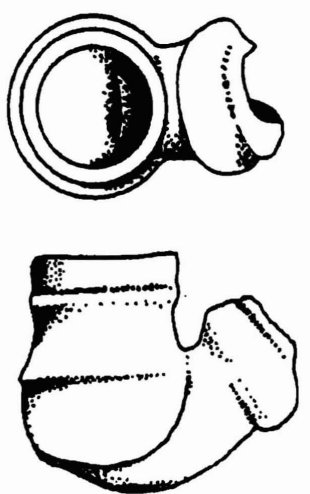

FIG. 14

T3 Cat. no. KN14
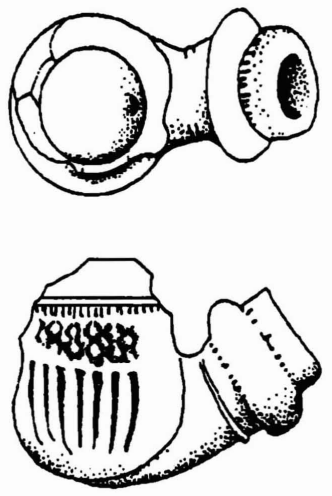

FIG. 15

T6

Type: Pipe with bowl, keel and slightly flared chimney for example T3 cat. no. KN14 (Fig. 14). This is similar to Hayes type IV, dated 18th century. ${ }^{11} \mathrm{~T} 3$ is made from tan-coloured clay, 

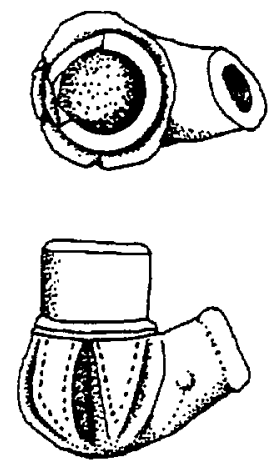

FIG. 16

T15

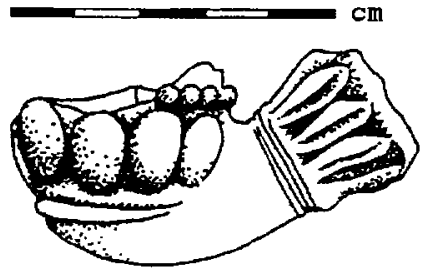

FIG. 17

T10 Cat. no. iZ

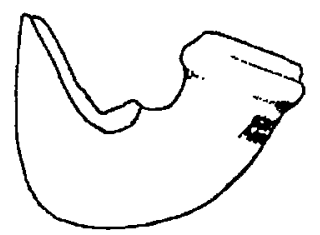

FIG. 18

T2 Cat. no. B1 3
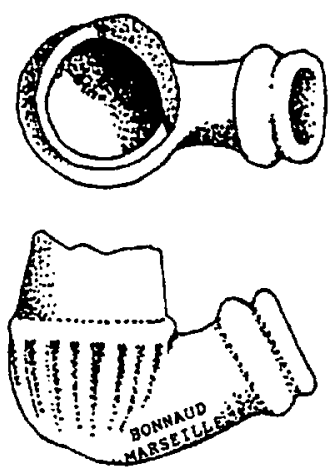

FIG. 19

Gozo22

burnished, with milled decoration on rim and shank. Also represented are bowls each with keel and straight rim T6 (Fig. 15) dated 18th to early 19th century. ${ }^{12}$ This example, uncatalogued, has an off-white clay body with gadrooning under rouletting and latticework decoration on the bowl and a milled shank end. There are pipes with no keel but with straight chimney T15 (Fig. 16). All of them are particularly common types in the central and eastern Mediterranean.

Decorative elements: Gadrooning on bowl or stem or both as on T10, cat. no. iZ in terracotta (Fig. 17) which has a square-ended keel with a $1 \mathrm{~cm}$. termination. Also common is milling, stitching, impressed hemispheres and incised lines.

Clay (which is loosely described by apparent colour and texture and has not been subject to proper scientific analysis): Terracotta.

Origin: One pipe in each collection is stamped as from the factory of BONNAUD MARSEILLES (in production 1824-1955) although they are distinctly different in style. T2 (Fig. 18) cat. no. B1 3 in chocolate brown clay was found in Tunis; no. 22 (Fig. 19) with a grey clay body under buff slip was found in Gozo.

\section{VI}

The following differences were observed between the two collections.

Type: Tunis has pipes with faceted chimney or stem, or both, example T17 (Fig. 20). This has a burnished chestnut body, the bowl faceted with floral decoration on each face over barley-sugar twists. A similarly faceted stem and chimney comes from Istanbul ${ }^{13}$ where at the end of the 18th century there were 60 workshops on pipemaker Hendek Street, Tophane, also Sarachane dated after $1850,{ }^{14}$ Athens and Corinth ${ }^{15}$ and Kastellorizo. ${ }^{16}$

Decoration: In Tunis there are pipes with Arabic script on bowl or stem possibly as a maker's mark, for example T4 (Fig. 21) in smooth orange paste and burnished finish. Decoration is impressed on both sides of the bowl and a maker's mark? is stamped on the right-hand side of the stem.

Clay: There is a significant number of white clay pipes in Tunis and charcoal grey ones in Gozo.

Origin: Tunis has a pipe from the factory of NOEL LYON, France, T1 (Fig. 22) made of white clay but much nicotine? staining. It is mould made and has No. 400 on the reverse side of the stem. Another has a Turkish? stamp on the base of bowl T21 (Fig. 23) a mould made pipe of smooth offwhite pipeclay. Another maker's mark? occurs under T9 (Fig. 2). The simple oval stamp on Gozo 15 (Fig. 24) is also found on pipes from Varna. ${ }^{17}$ 

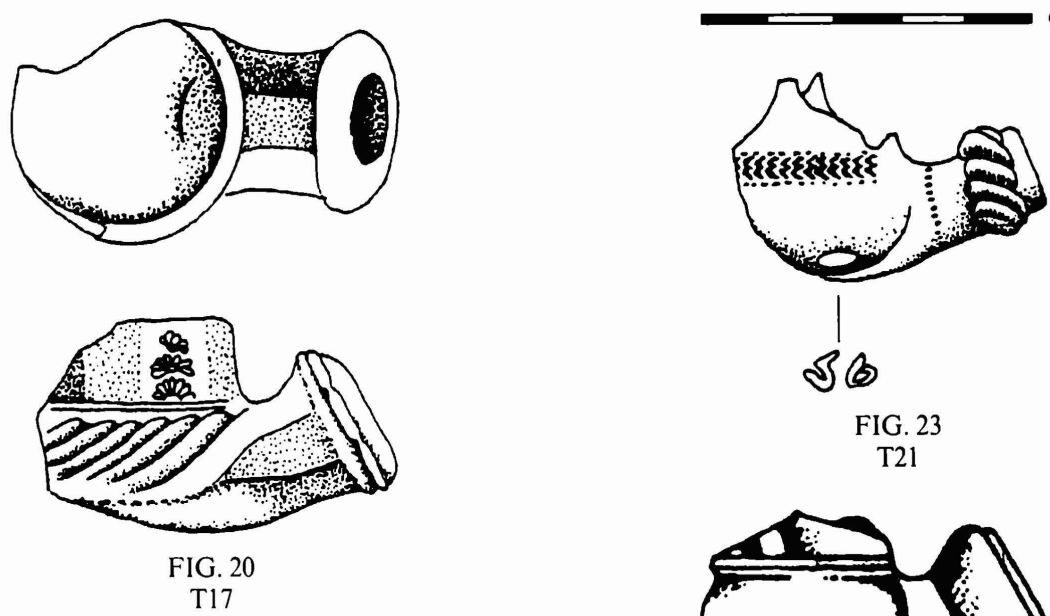

FIG. 23

T21

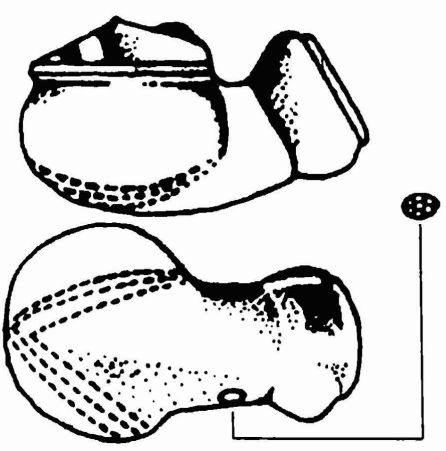

FIG. 24

Gozol5
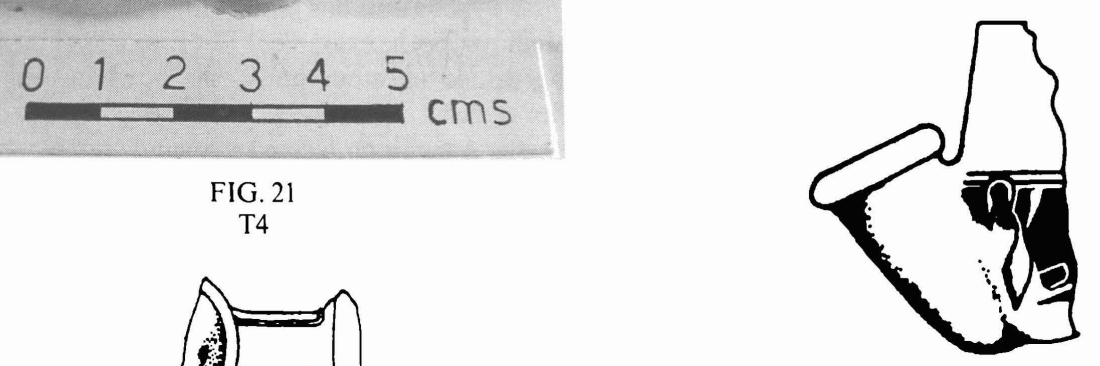

FIG. 25

Gozo21
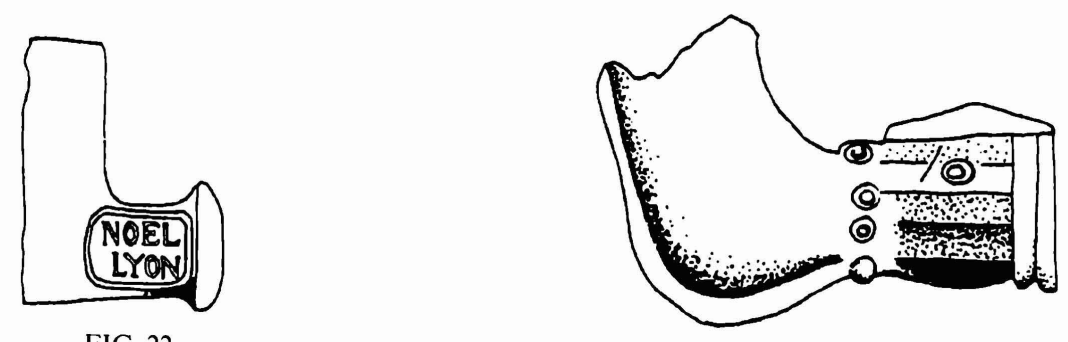

FIG. 22

T1

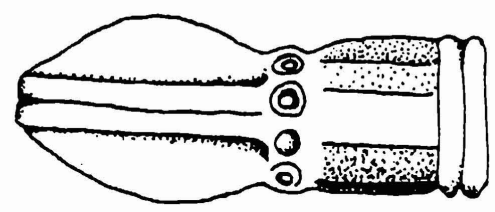

FIG. 26

T12 Cat. no. B2 29 

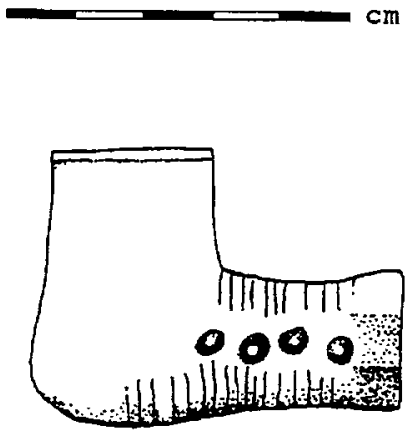

FIG. 27

T14

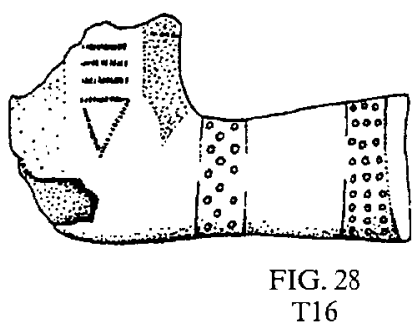

Some Tunisian pipes have blue, or blue and white glaze $(\mathrm{T} 9 \mathrm{~b}, \mathrm{c})$, a feature less common in Gozo which has just the one glazed in transparent over brown slip No. 21 (Fig. 25) provenance: Xlendi Bay 1991 (although three glazed pipes, as yet unpublished, have recently come to light in Malta).

The majority of all pipes have the bowl set at an acute angle to the stem. There is however a 'family' of pipes in Tunis whose bowl is set at a right or an obtuse angle to the stem, see T9 (Fig. 2), also T12 cat. no. B2 29 made of a pinkish gritty paste. Strips of clay were added to the top of the shank and under and around the bowl of this artefact. The stem is faceted and has an impressed pattern of moulded hemispheres around the neck (Fig. 26), T14 (Fig. 27) in pale terracotta with incised and impressed decoration on the stem and T16 (Fig. 28) in yellowy white clay of very uneven thickness. These all have a distinctly 'local' look.

\section{VII}

\section{CONCLUSION}

In contrasting the two collections I make no pretence in comparing like with like in that the Gozitan collection has been studied in some detail, whilst the Tunisian collection would take time to document thoroughly. As quoted in the introductory chapter on Gozo, clay tobacco pipes are still a folk memory there amongst an older generation, some of whom will describe their experiences of working in North Africa and other places around the Mediterranean littoral. In Sannat, Gozo, today there is Marsilija street, so named after the number of emigrant males working in Marseilles during the 19th-century salt trade. In both collections there are examples of 19th-century chibouk pipes showing that French manufacturers were competing for this market and that small numbers of their products were finding their way into the Maltese and North African markets through the port of Marseilles.

In his book the Revd Dr Joseph Bezzina quotes from the Archiepiscopal Archives in Malta, 'Some ecclesiasts were indulging in the not commendable but increasingly popular habit of smoking a pipe. Due to their state and dignity they were prohibited to smoke in public, but were free to do so in private'. ${ }^{18}$ These circumstances pertained between 1801 and 1840. 'A Maltese Pothouse' by Brockdorff, who was painting local scenes around 1825 , shows the proprietor smoking a chiboukstyle pipe. In the Fine Arts Museum in Valletta a late 18th-century copper plate engraving by Zimmelli shows a peasant in wedding costume with a similar pipe. Tobacco was widely used in the Maltese Islands by the mid 17 th century and taxed from 1673. This well established habit of smoking had to be supported and the wherewithal imported, in part, if not its entirety, from North Africa.

Examination of the Tunis collection has identified a particular style of pipe which was probably made locally and which accounts for two-thirds of the pipes found there. There is no evidence whatsoever that this style of Tunis pipe was imported into the Maltese Islands either commercially or as personal effects. All the features of style and decoration which are common to both collections are also commonly found in pipes wherever Ottoman Turks had influence. Of course international contacts were maintained throughout the Mediterranean from the time tobacco was introduce $c$. 1600 and maritime activity would have been one way to maintain those contacts. The Maltese were in a good geographical and nautical position to do that.

At this stage, however, the author does not feel confident enough to say more than that in Gozo most pipes appear to have come from outside the island, whilst in Tunisia most were made locally, although a significant percentage of the Ottoman style were imported. The woman from Rabat, Malta, who said that North African nationals sold pipes that were cream-coloured, 
curved and nicely shaped could conceivably be describing a version of the standard Tunis pipe, or possibly Gozo No. 21 (Fig. 25). Red clays, mentioned by the 80 -year-old from Zejtun, have been fashionable since the late 17 th century, when gulbahar clay imported from the lake Van area in Asia Minor was used by the pipemakers of Istanbul. Three of the 22 Gozo pipes are described as red fabric, although they were not burnished like quality Ottoman products. Were Tunisian pipes traded to Gozo? That still remains a possibility which further work may help clarify.

\section{ACKNOWLEDGEMENTS}

My grateful thanks to Colin Stevenson, Director of the British Council in Tunis, for his help and encouragement with this paper, and to Justin McGuinness for his generosity with translations and source material on the Magreb; also to Guido Lanfranco who elicited information from callers during his weekly radio programme on RTK Malta.

18 Park Road, Sherington, Bucks MK16 9PG

\section{APPENDIX}

A note on the petrology of a tobacco pipe thought to have been made in Tunis, Tunisia

$$
\text { by D. F. Williams }
$$

A petrological examination was undertaken on a ceramic pipe bowl thought on typological grounds to have been made in Tunis. The analysis was done to see if the clay fabric could be sufficiently characterized to say if a Tunis origin is possible or not in this case. As an aid to sourcing the pipe, a sample of distinctive 'Lions Paw' glazed ceramic tile, known to have been made at the Bab Souika factory in Tunis during the 18th century, was also submitted as a comparative sample. The latter was used to see if similar clays might have been employed in both items.

The pipe bowl is a hard, smoothish, moderately sandy fabric, and is a light grey in colour (between Munsell 10TR 7/1-7/2). A small sample was detached from the pipe, ground down to a suitable thickness and then examined in thin section under the petrological microscope. This showed that the most common non-plastic inclusions present in the clay matrix consist of frequent ill-sorted subangular quartz grains, ranging up to $0.5 \mathrm{~mm}$. in size. Also present are a scatter of small pieces of cryptocrystalline limestone voids, which undoubtedly once contained limestone that has since leached out, leaving behind reaction rims, and some iron oxides.

A thin section taken from the 'Lions Paw' tile was fond to contain a similar range of non-plastic inclusions, though with slightly more pieces of limestone present. In this connection, it is also worth noting that a similar quartz-limestone fabric has previously been noted in pottery, brick and tile thought to have been made in Roman Carthage, part of modern Tunis (Fulford and Peacock 1984, Fabric 2.1-2, pp. 14-15 and fabric C, p. 243).

The non-plastic inclusions present in the pipe bowl are all fairly common. It would be unsafe to conclude from a single sample, therefore, that because the similarities of fabric with material considered to, have been made in Tunis in ancient and modern times, that Tunis must also be the source for the pipe.

However, the latter results, which must reflect the use of local clays, do appear very similar in both mineral content and also texturally to the pipe bowl. On this evidence, a Tunis origin for the pipe bowl seems to be quite feasible.

\section{BIBLIOGRAPHY}

Fulford, M. G. and Peacock, D. P. S. 1984, Excavations at Carthage: The British Mission, Vol. 1.2. Sheffield.

\section{NOTES}

1 Pers. comm. Justin McGuinness.

${ }^{2}$ Robinson, R. C. W. 1985 . 'Tobacco pipes of Corinth and the Athenian Agora', Hesperia, 54, 149-203.

${ }^{3}$ Wood, J. 1992. 'Pipes from Gozo (Malta)', Society for Clay Pipe Research Newsletter 25, 8-9.

${ }^{4}$ Price, C. A. 1954. Malta and the Maltese. Georgian House, Melbourne.

${ }^{5}$ Hall, J. 1991. 'Evidence of smoking aboard the Santo Antonio de Tanna', Institute of Nautical Archaeology Quarterly, 18.2, 18-23.

${ }^{6}$ Jack, R. I. 1990. 'Clay pipes from Thailand', Society for Clay Pipe Research Newsletter 27, 15-18.

${ }^{7}$ Robinson, op. cit. in note $1,162$.

${ }^{8}$ Hayes, J. W. 1980. 'Turkish clay pipes; a provisional typology', in Davey, P. (ed.), The Archaeology of the Clay Tobacco Pipe, BAR International Series $92,3-10$.

${ }^{9}$ In the Koutlidis Collection, Greece.

${ }^{10}$ Robinson, op. cit., C135 pl. 60.

${ }^{11}$ Hayes, op. cit., 5.

${ }^{12}$ Hayes, op. cit., type XXIII.

${ }^{13}$ Bakla, E. 1985. 'Lulecilika', Antika 5, 6-8. 
${ }^{14}$ Hayes, op. cit., type $X$.

${ }^{15}$ Robinson, op. cit., pls 56-62.

${ }^{16}$ Wood, J. 1990. 'Pipes from the island of Kastellorizo', Society for Clay Pipe Research Newsletter 25, $8-9$.
${ }^{17}$ Pers. comm. St J. Simpson; Stanceva, M. 1985/6. 'La confection de pipes en Bulgarie', Bulletin du Musée des arts decoratifs (Beograd), 19/20, 129-37. ${ }^{18}$ Bezzina, J. 1985. Religion and Politics in a Crown Colony, Bugelli Publications, Valletta. 